\title{
Muerte y cambios de mentalidad en la Europa del siglo XIV
}

\author{
Death and mentality changes in 14th-century Europe
}

Irene Lázaro Romero,

Máster en Métodos y Técnicas de Investigación en Historia, Universidad Nacional de Educación a Distancia, España (ilazaroromero@gmail.com)

RESUMEN: Durante el siglo XIV, quizá debido a la fuerte crisis que sufrió Europa en este siglo, se dieron una serie de cambios en la mentalidad colectiva que afectaron a la devoción y al tipo de relación que el fiel tenía con Dios. Imperó una mística más intimista y esto se refleja en la visión que se tenía de la muerte. El individualismo hizo que se tendiera a priorizar el juicio del alma en el momento mismo de la muerte frente a la importancia que había tenido el Juicio Final, colectivo, en siglos anteriores. Estos cambios de mentalidad en relación con la muerte se dejaron sentir en el ritual funerario, que cambió adaptándose a las nuevas ideas. También ejerció influencia en el arte, especialmente en los sepulcros.

PALABRAS CLAVE: Crisis del siglo XIV, muerte, devotio moderna, arte macabro.

\begin{abstract}
During the 14th Century, possibly because of the crisis that Europe suffered during these years, a series of changes in the mentality arose in relation with the devotion and the relationship of the faithful with God. A new and intimist religious sentiment developed and it changed the way in which people perceived death. Individualism lead to a preference for the judgement of the soul in the precise moment of the death of the individual as opposed to the collective Final Judgement which was extremely important in previous centuries. These changes in the mentality regarding death transformed the funeral rites, that adapted to the new ideas. It also had a heavy influx on art, especially in the sepulchres.
\end{abstract}

KEYWORDS: Crisis of the 14th Century, death, devotio moderna, macabre art. 
Desde la Alta Edad Media, se distinguía entre dos tipos de muerte. En primer lugar, estaba la muerte del cuerpo, la muerte física, que se conocía como muerte primera. Ésta era un castigo por los pecados cometidos por el hombre. Se consideraba que resultaba dolorosa por la separación de cuerpo y alma en el difunto. Sin embargo, el buen cristiano no debía temer la muerte primera, ya que era una puerta para la vida después de la muerte, permitía alcanzar la salvación. Había que aceptarla de manera estoica para poder lograr la vida eterna. De este modo, se veía la vida como un peregrinar, siendo el pecado el principal obstáculo que se encontraba el peregrino para llegar a su destino final: la Gloria (Haindl, 2009, pp. 106-108).

La muerte segunda, en cambio, sí era algo que había que temer, era la condena eterna. Aquellos que pecaban sufrirían los castigos del infierno por toda la eternidad, cuyos horrores se mostraban con gran detalle en las portadas de las catedrales y todos los fieles los tenían bien presentes. Esta diferenciación de la muerte primera o física y la muerte segunda o condena la encontramos ya desde el año 252 en De Mortalitate de Cipriano de Cartago, primer tratado de la muerte medieval, y será desarrollada por San Ambrosio (Haindl, 2009, p. 108).

La importancia fundamental que se da al tránsito después de la muerte en la tradición judeocristiana, llevó necesariamente a un desapego por la vida. Se consideraba que la vida estaba plagada de dolor y sufrimiento y toda esperanza estaba puesta en la salvación. En este contexto, surgen una serie de obras literarias que muestran una aversión por la vida terrenal, su carácter perecedero y sus placeres efímeros: “¿Quién ha pasado ni siquiera un solo día totalmente agradable y placentero ...?” (Huizinga, 2008, p. 188) refiere el futuro papa, Inocencio III, en De Contemptu Mundi, que alcanzó su máxima popularidad a finales de la Edad Media. No deja de sorprender que sea este personaje tan favorecido el que escribe estas palabras.

La trascendencia del alma, no obstante, no es algo que ocurriera inmediatamente después de la muerte corporal. La salvación de las almas de los justos y la condenación de las almas de los pecadores se llevará a cabo en el Juicio Final. Hasta el año 1000 se consideraba que la muerte era simplemente un sueño que esperaba la segunda venida de Cristo y el juicio de las almas (Haindl, 2009, p. 106). Sin embargo, esta espera del Juicio Final perderá fuerza a medida que nos aproximamos a la Baja Edad Media, especialmente a partir del siglo XIV debido a un cambio de mentalidad y religiosidad. 


\section{Del juicio colectivo al juicio individual}

El siglo XIV estuvo marcado por una fuerte crisis que afectó a todos los sectores de la población (Tuchman, 1978). Una serie de malas cosechas, que se vieron agravadas por las bajas temperaturas de la llamada Pequeña Edad de Hielo, provocaron hambrunas terribles entre la población. Al agotamiento de los recursos también contribuyeron las guerras internas que estaba sufriendo Europa, especialmente la Guerra de los Cien Años, que se prolongó durante todo el siglo. A los gastos propios de una contienda de estas dimensiones, también hay que sumar las pérdidas de cultivos arrasados y el ganado extraviado. El hambre llevó a revueltas campesinas y levantamientos que acabaron de manera violenta. Por último, cuando la sociedad estaba más débil, una epidemia de peste negra diezmó la población.

Muchos han querido ver en la crisis del siglo XIV el origen del cambio de mentalidad y religiosidad que vivió la sociedad medieval durante este periodo. Sin embargo, el precedente estaba en el pensamiento de filósofos del siglo XIII como Duns Scoto o Guillermo de Ockham. (Huete, 1998, p. 56). Se condenó el pensamiento de Santo Tomás de Aquino, que había tratado por todos los medios de conciliar fe y razón. Frente a esto, los pensadores mencionados insistieron en la separación absoluta de fe y razón, creyeron que era imposible entender las verdades de fe mediante el pensamiento. De este modo, se exhortó a profundizar en el conocimiento del mundo natural y la división entre lo celestial y lo terrenal fue mayor (Orlandís, 1998, pp. 424-426).

Estos pensamientos cristalizaron en la devotio moderna, una nueva forma de entender la devoción de manera más intimista y privada que en siglos anteriores. Imperaba una búsqueda de la mística en solitario, alcanzada mediante la oración, la reflexión o la contemplación de imágenes, frente a las grandes misas colectivas (Orlandís, 1998, pp. 430-432). Esta relación íntima con Dios era uno de los pilares fundamentales de las predicaciones de las órdenes mendicantes, los predicadores criticaban todo lo material considerándolo vano y frívolo y resaltaban la importancia de la oración en privado. Subrayaban la importancia de profundizar en la fe en solitario.

Esta nueva devoción coincide con un auge del individualismo por primera vez desde la Antigüedad. El individuo medieval empieza a ser consciente del yo, en oposición a la alteridad. La persona cobra importancia con respecto al resto. Esto se refleja en algunas costumbres de la época 
como la necesidad de tener una habitación propia, la aparición del studiolo y una relación más directa con Dios (Ruiz García, 2011, p. 315).

La individualidad imperante influirá también en la visión de la muerte. El Juicio Final, colectivo, obsesión de la Alta Edad Media, perderá importancia en favor de un juicio particular, individual, que tiene lugar en el propio lecho de muerte. Jean Gerson, canciller de la Universidad de París, llevó estas ideas al Concilio de Constanza (1414-1418) ya en el siglo XV (Ruiz García, 2011, pp. 317-318). De este modo, el tránsito del alma del difunto en el momento de la muerte se convirtió en algo decisivo. El hombre que había pecado podía ser redimido en el lecho de muerte, pero se lo jugaba todo en esos últimos momentos de su vida. Esto llevó a un terror a la muerte súbita o imprevista, especialmente aquella que era violenta o por sorpresa, que no permitiera al difunto prepararse con antelación. La buena muerte era aquella que sucedía en la paz del hogar con el moribundo rodeado de los suyos.

Los comentarios acerca de la muerte de Jean Gerson fueron codificados por un autor anónimo en el Ars Bene Moriendi. Este texto describía las tentaciones que el moribundo sufría durante la agonía de la muerte y el modo de luchar contra ellas haciendo uso de la fe en Dios y la esperanza en la salvación. Era una suerte de manual para conseguir una buena muerte. El Ars Moriendi se fue simplificando y poblando de imágenes para que incluso las capas más humildes de la población pudieran entender su mensaje (Ruiz García, 2011, pp. 317-320). El Ars Moriendi representa al moribundo en el lecho rodeado de su familia. De un lado, los enviados del demonio tratan de tentarle y, del otro, el ángel del Señor acude en su ayuda para mostrarle el camino a la salvación. 


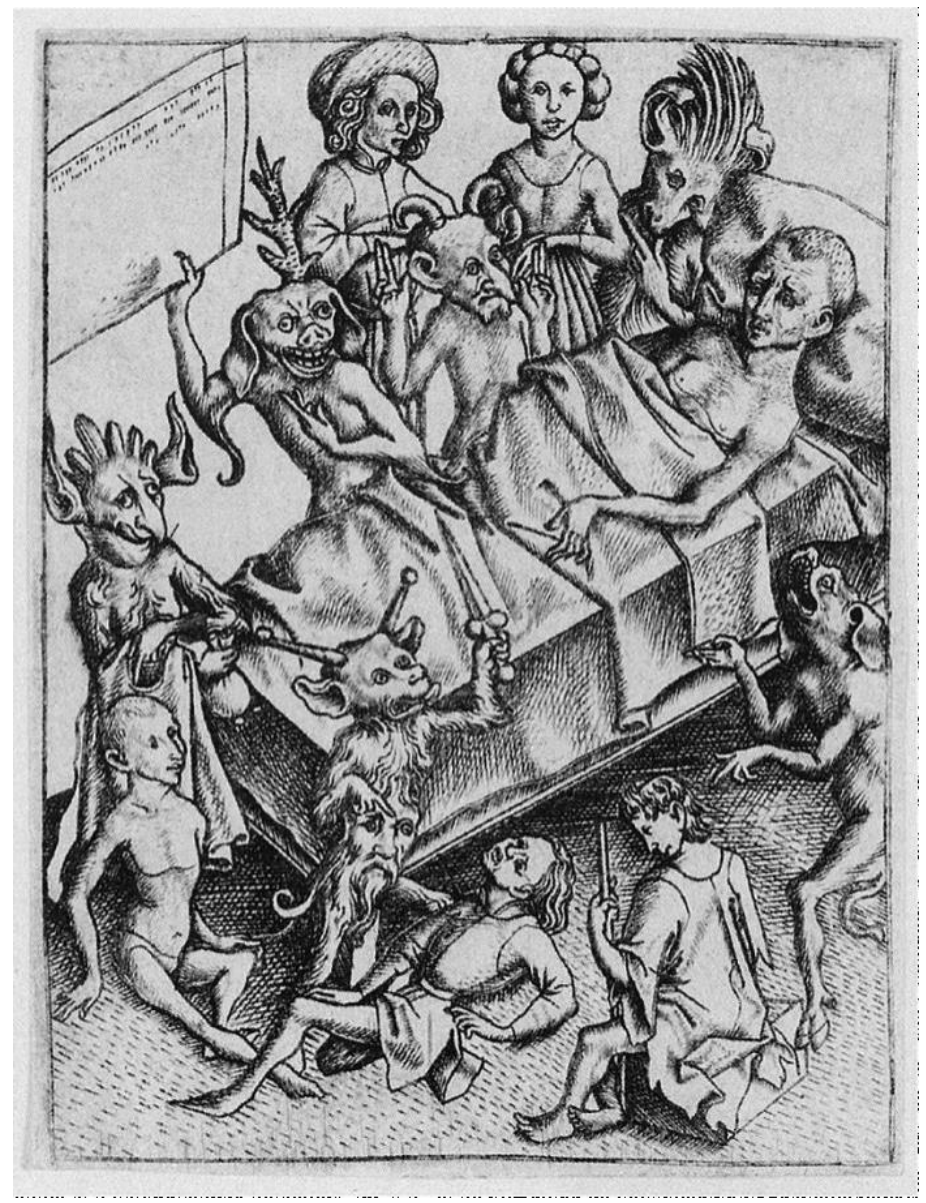

1. Ars Moriendi del Maestro E. S., Tentación contra la desesperación, lámina 177, c. 1460.

Uno de los ejemplos más representativos es el Ars Moriendi conservado en el Museo Ashmolean de Oxford, de un grabador alemán conocido como Maestro E. S. Una de las tentaciones que el moribundo debe vencer es la de la desesperación. Ante el lecho del difunto, se materializan las personificaciones de los pecados cometidos por el agonizante: la mujer con la que pecó, el hombre al que se negó a dar abrigo, el mendigo al que no entregó limosna y el hombre al que asesinó. Un demonio sostiene una hoja de papel en la que se enumeran los pecados del moribundo. El mensaje subyacente es que, a pesar de todos estos pecados, siempre existe salvación mediante el arrepentimiento sincero. Se consideraba que la misericordia de Dios era mayor que el más grande de los pecados (Mâle, 1982, p. 138).

Desde su aparición a principios del siglo XV, estos libritos gozaron de una gran popularidad porque respondían muy bien a la necesidad de consuelo de una sociedad cada vez más individualista preocupada por su propia salvación. Sin embargo, no bastaba con vencer las tentaciones para alcanzar la salvación. El enfermo debía cumplir un riguroso rito funerario. 


\section{El rito funerario a finales de la Edad Media}

La buena muerte, como ya se ha descrito, era aquella que alcanzaba al moribundo preparado y rodeado de los suyos, en lo que se conocía como "muerte domada". Para ello era necesario cumplir con todo un conjunto de prácticas cuando se acercaba el momento de la muerte. La salvación del alma mediante el cumplimiento de este ritual era tan importante que, cuando un enfermo se encontraba grave, se cejaba en el empeño de curar su cuerpo para tratar de salvar su alma. (Haindl, 2009, p. 111).

Había una serie de pasos que había que seguir para alcanzar la buena muerte que trataban de controlar en la medida de lo posible el desorden producido por el fallecimiento de una persona. En primer lugar, el moribundo decía sus últimas voluntades y hacía testamento. Delante de varios testigos, nombraba a su heredero. En el testamento también figuraban las especificaciones de su enterramiento, así como las misas que quería que se dijeran en su nombre después de muerto. Esta era una manera de propiciar la salvación del alma. A continuación, se desprendía de sus bienes terrenales: objetos de valor, lienzos y paños... y se despedía de sus seres queridos. Era muy importante que hubiera testigos para asegurar que se cumplían las últimas voluntades del finado, pero también para transmitir el mensaje de aceptación de la muerte y renuncia a todo lo terrenal. Liberado de sus posesiones, se le daba alivio espiritual: El moribundo realizaba su última confesión y recibía la extremaunción. Durante el tiempo en que estaba agonizante, se velaba al enfermo hasta que llegaba el momento de la muerte.

En cuanto a la parte pública del rito, la familia acompañaba el ataúd en cortejo fúnebre por estricto orden jerárquico y portando cirios. Les seguían los criados y algunos pobres y mendigos. Se daba un banquete público y limosnas a los pobres como el finado había dejado estipulado en su testamento. Se trasladaba el cuerpo al lugar elegido para su enterramiento, o si era una persona de la suficiente consideración social, se exponía su cuerpo o efigie durante días. Las manifestaciones de duelo también eran públicas: las mujeres se arañaban el rostro, se vestía de negro... En el caso de fallecimiento de un rey, se cerraban los negocios y los oficiales vestían paños bastos (Ladero, 2004, p. 98).

En cambio, la muerte no terminaba en la tumba. Se celebraban aniversarios del difunto de manera anual en los que se llevaba a cabo un banquete. Además, era habitual que el difunto hubiera 
encargado en su testamento una serie de servicios religiosos dichos en su nombre: Aniversarios perpetuos, misas de Requiem... La presencia de los muertos en el mundo de los vivos era constante. Afortunadamente conservamos gran número de testamentos que nos hablan de estas prácticas. Las misas de difunto, el enterramiento y el sepulcro y las limosnas recortaban en mucho la cantidad de la herencia de los familiares. Por este motivo, se dictaron leyes restrictivas contra los funerales demasiado abundantes que dejaban a los herederos en la pobreza (Ladero, 2004, pp. 29-30).

\section{Los nuevos sepulcros}

Antes del siglo XIV la igualdad en la muerte era total. Unos pocos años después de sepultar el cadáver, los huesos se exhumaban y pasaban a formar parte de osarios donde se convertían en esqueletos anónimos (Mâle, 1982). A partir del auge de la individualidad y del juicio particular, se fue popularizando la idea de dar un enterramiento individualizado. Las familias adineradas desenterraban a sus antepasados de los sepulcros colectivos para darles una nueva dignidad. Los que podían permitírselo, fundaban colegiatas en las que se enterraba toda la familia o bien lo hacían en capillas particulares.

Así, el sepulcro se convierte en un objeto fundamental en el que se vuelcan todos los esfuerzos económicos y artísticos. El sepulcro tenía gran importancia también en el siglo anterior, creándose algunos de los más bellos monumentos funerarios que hemos conservado. Sin embargo, cambiará el gusto en lo que se refiere a efigies funerarias a mediados del siglo XIV a raíz de la nueva devoción y visión de la muerte que se ha descrito.

Los sepulcros del XIII presentan al finado yacente, recostado sobre almohadones y con las manos en oración. Destacan por su placidez y serenidad. Los retratos no buscan necesariamente el parecido con el modelo, sino que optan por representarlo bello y joven, con la edad perfecta de treinta y tres años con la que los cristianos resucitarán el día del Juicio Final. Más que esperar a la Gloria, parece que ya participan de ella, tan serenos y bellos.

Los sepulcros pertenecientes a los Plantagenet que se encuentran en la abadía de Fontevraud, son el ejemplo más temprano de esta representación del difunto yacente sobre la tapa del sepulcro (Geese, 2004, p. 346). Fueron esculpidos en el primer cuarto del siglo XIII y presentan a los finados ricamente amortajados y sus rostros son juveniles y un tanto arquetípicos. Muestran a los difuntos 
vivos, con los ojos abiertos, ni siquiera parecen haber expirado, sino que esperan con calma la llegada del Juicio Final. Llama la atención en especial la actitud de Leonor de Aquitania, que aguarda leyendo un libro que posa en su regazo.

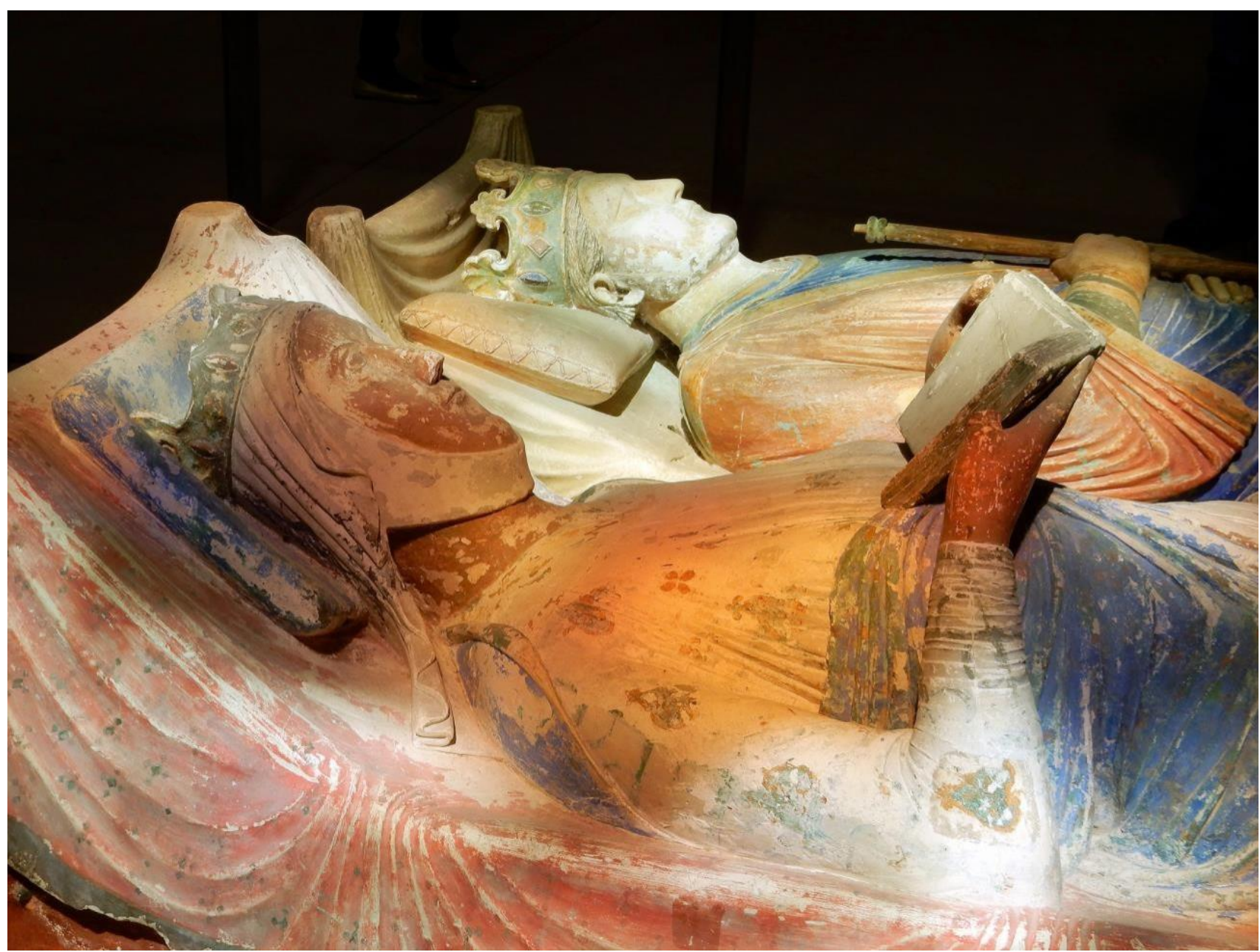

2. Sepulcros de Leonor de Aquitania y Enrique II Plantagenet, c. 1200 - 1225, Abadía de Fontevraud en Fontevraud-

l'Abbaye (Francia).

En cambio, en el siglo XIV el sepulcro se concibió de una manera distinta. El retrato del finado se hizo mucho más realista, captando la fisionomía del difunto con mucha naturalidad. De este modo, a diferencia de las efigies anteriores que eran no perseguían la veracidad en los rasgos, en el siglo XIV son más individualizadas, buscando la identificación de la persona. Hay que poner este naturalismo en línea con la corriente de realismo y la importancia de retrato que se da en el arte de este periodo. Este realismo en las representaciones de los difuntos se llevará al extremo con la proliferación de sepulcros de transi o de tránsido. En ellos, la figura del yacente aparece descompuesta y con gusanos comiendo su carne y alimañas trepando por su cuerpo. 
Quizá el ejemplo más significativo de sepulcro de transi sea el de John Fitz Alan, XIV Conde de Arundel. Fue realizada hacia 1435 para la capilla del castillo Arundel de Sussex. El cadáver se representa con la carne en descomposición y la boca abierta, retorciéndose. Está cubierto con una mortaja de tela basta. Sobre esta imagen grotesca se representa, sobre una estructura sobreelevada de arcos calados, la efigie idealizada del difunto. En esta figura del cuerpo superior, el finado aparece sereno, con las manos en gesto de oración y vistiendo armadura. De esta manera, el cadáver descompuesto aparece como una suerte de espejo terrible de la figura del yacente, cuyo contraste enfatiza aún más su significado macabro (González y Berzal, 2014, pp. 73-74).

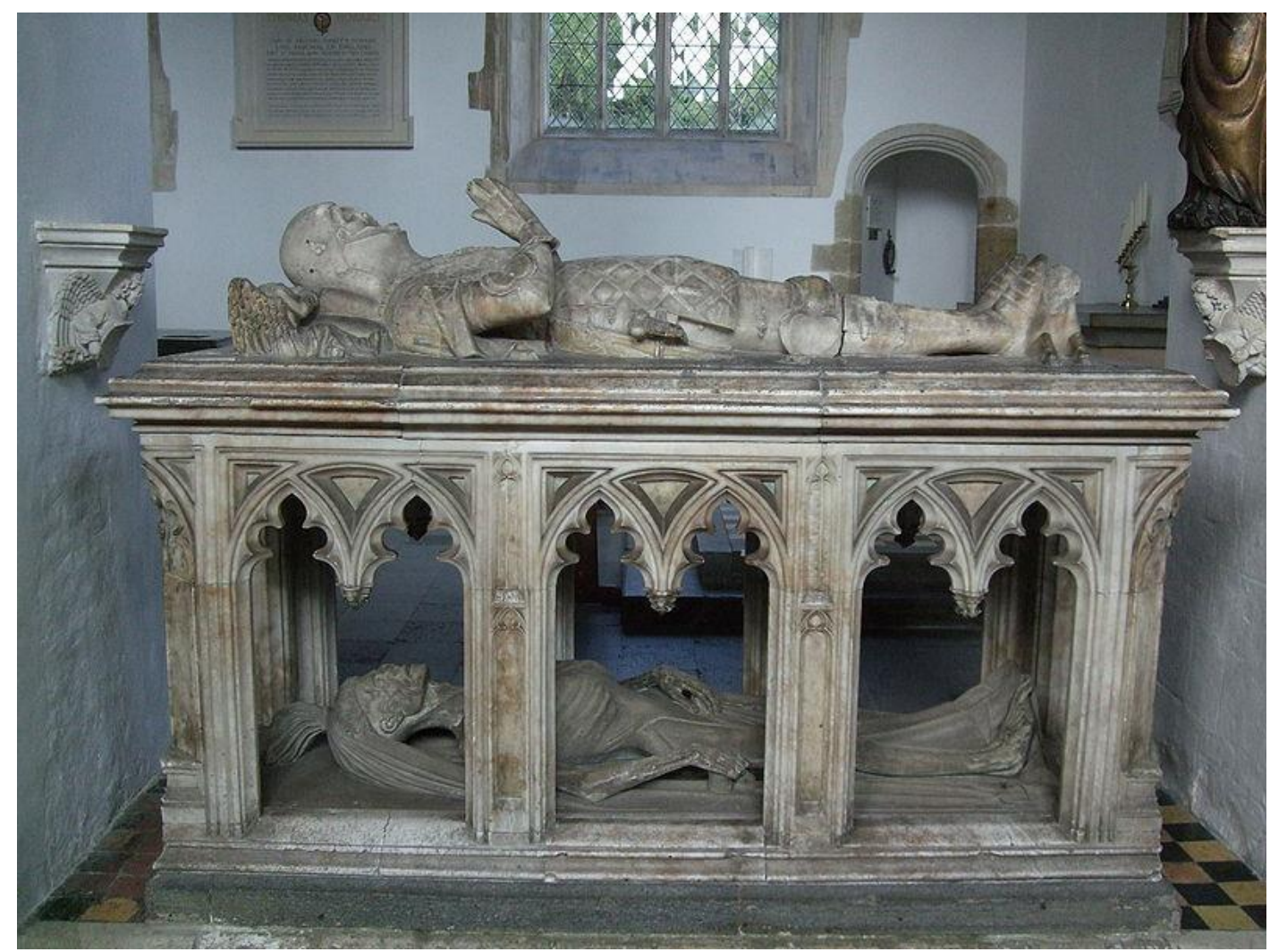

3. Monumento funerario de John Fitz Alan, c. 1435, Capilla del Castillo de Arundell, West Sussex (Inglaterra).

Estos sorprendentes sepulcros tienen sentido en el contexto del cambio de mentalidad del siglo XIV. Huizinga (2009, pp. 183-199) consideró que surgieron como una reacción al apego por la belleza y lo estético del final de la Edad Media. La muerte, como pérdida de esta belleza física, se consideraba algo deplorable y terrible. También se explica por la corriente del naturalismo y como gesto de falsa humildad por parte del finado (González y Berzal, 2014), de manera similar a cómo numerosos personajes seglares se hacían enterrar vistiendo el hábito de una orden religiosa. Esta idea queda subrayada por el hecho de que muchos de los sepulcros llevan inscripciones exhortando al espectador a que rece por el difunto. También hay quién cree que estas imágenes tienen, en último 
término, un mensaje salvífico, defienden que los gusanos están abandonando el cuerpo más que penetrando en él (Aberth, 2005, p. 171). Pudiera también estar relacionado con el desapego por la vida terrenal y sus goces perecederos que impera en la literatura de la época, como en este pasaje del poema Le Miroir de Mort citado por Huizinga (2008, p. 196):

\author{
"Y este cuerpo vuestro, vil e inmundo \\ Lo perderéis para siempre jamás: \\ Será carne corrupta \\ Pasto de la tierra y de los gusanos"
}

No era el naturalismo el único modo de mostrar la individualidad del difunto, aún después de muerto. A finales de la Edad Media las obras se llenan de los escudos y divisas de los que las encargan y los sepulcros no son una excepción. Los emblemas heráldicos identificaban al finado, lo que demuestra el interés del individuo por ser recordado aún después de la muerte, es un deseo por permanecer en el mundo terrenal al menos en imagen. La reproducción de los escudos de armas es consecuencia de un afán caballeresco de obtener gloria postrera, que, contrariamente a la creencia popular, no había desaparecido en la Edad Media (Huete, 1998, pp. 26-37). Además, habla del linaje y la grandeza familiar. Asimismo, a menudo se enterraba a los familiares en proximidad creyendo así garantizar su reunión en el Paraíso.

\title{
El cambio de mentalidad en el resto de las artes
}

Si bien se puede pensar que los sepulcros son las manifestaciones artísticas que mejor reflejan el cambio de mentalidad con respecto a la muerte ocurrido a mediados del siglo XIV, este efecto también se dejó sentir en el resto de las artes de la época. Al igual que el abad Suger en el siglo XII concebía la divinidad como una irradiación de luz, ahora el diálogo con la divinidad se relaciona con un intercambio de miradas. El arte era un vehículo de diálogo con Dios, por lo que adquirió casi la misma importancia que las reliquias (Duby, 1998). Con esta idea, proliferaron obras de arte portátiles, a menudo no encargadas directamente al artista sino obtenidas en el mercado del arte. Cualquier lugar podía convertirse en un espacio de culto gracias a estas obras que se podían transportar fácilmente. Igualmente, alcanzan un éxito fundamental los Libros de Horas, que permitían la oración privada y una devoción más intimista. 
Para los pobres, que no podían permitirse adquirir este tipo de piezas, los predicadores repartían con frecuencia grabados que simplificaban el mensaje de la Biblia. Destacan entre estos folletines las Biblias de los pobres. También se repartían estampas que representaban temas iconográficos populares con más sencillez. Su función era la de instruir, pero también se utilizaban como objetos de devoción, decorando el hogar o incluso se cosían a las ropas. Junto a estos, se repartían también Ars Moriendi, que alcanzaron una gran difusión a partir de la invención de la imprenta (Ruiz García, 2011).

A la hora de representar a los muertos, antes que el esqueleto se suele preferir una momia reseca. Algunos suelos tienen la propiedad de conservar los cuerpos y estas momias eran expuestas con frecuencia en iglesias y otros lugares. La momia parece seguir participando de la vida más que el esqueleto y es esa la imagen que se prefiere para causar el máximo efecto (Mâle, 1982).

La representación de la muerte en el arte se relaciona con el resurgimiento de temas artísticos de carácter macabro que, si bien ya existían anteriormente, es ahora cuando alcanzan su mayor difusión. Así, reaparecen las Danzas Macabras, en las que la muerte invita a un individuo de cada clase social y tipo humano a que le acompañe en una danza fatal que culminará con su muerte. Democrática en apariencia, la muerte se lleva a los hombres por estricto orden jerárquico, de lo que se desprende que las diferencias sociales y económicas no se borran completamente tras la muerte (González, 2014, pp. 25-26).

La danza de Clusone, pintada por Giacomo Borlone de Buschis en 1485, muestra un fuerte contraste entre los vivos y los muertos. Los vivos se presentan con mucha individualidad y variedad en sus ropajes, aludiendo al estamento social al que pertenecen. Los muertos, en cambio, se presentan como esqueletos idénticos que, cogiendo a los vivos del brazo, los llevan a su muerte. Como es habitual en las danzas macabras, los esqueletos son dinámicos: Se aprecia que están bailando por el movimiento que el artista ha dado a sus extremidades, y se dirigen a los vivos con audaces gestos. Los hombres, por el contrario, presentan una actitud rígida y un ademán compungido, tratando de resistirse a su destino. 


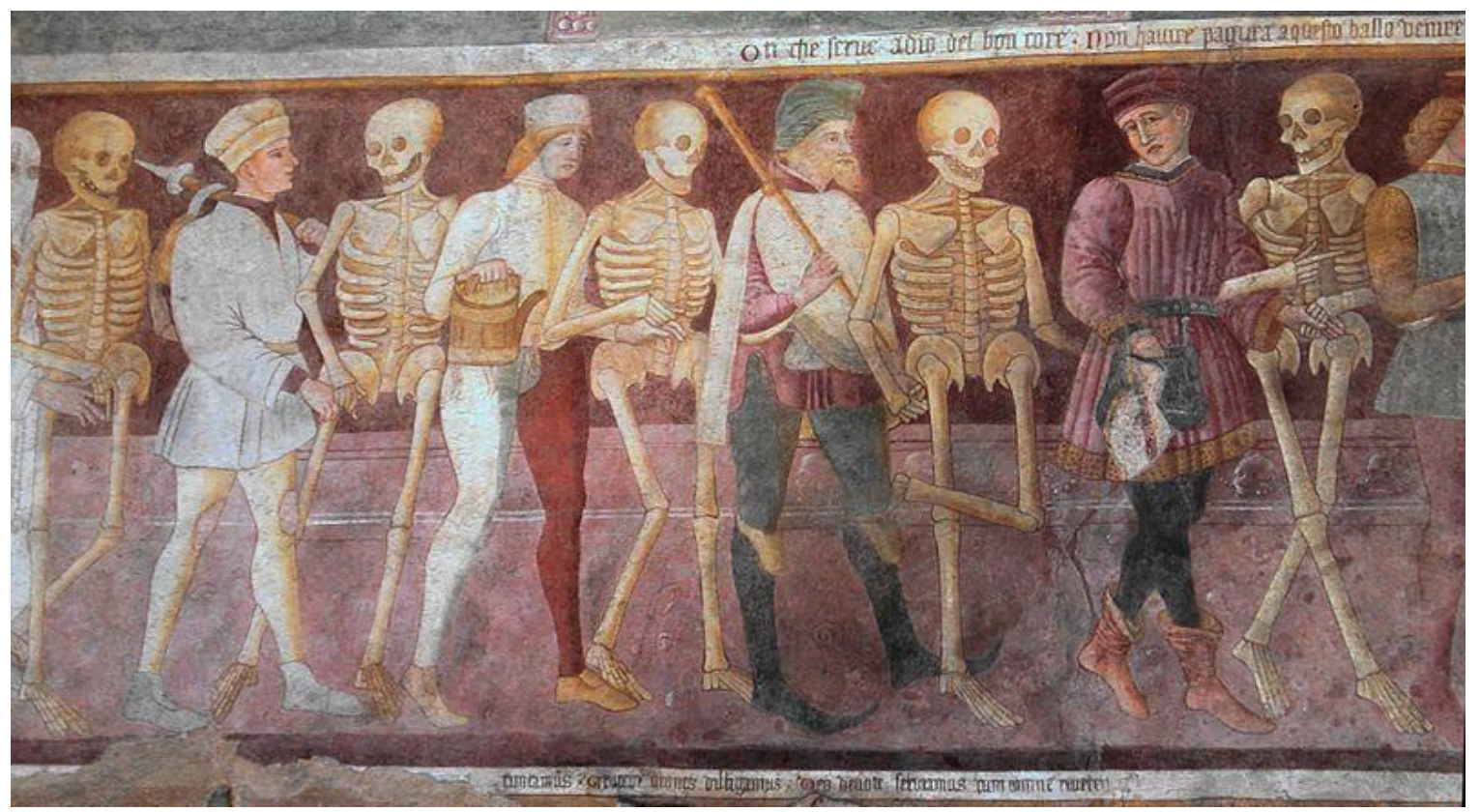

4. Giacomo Borlone de Buschis, pinturas del claustro del Oratorio dei Disciplini de Clusone (Italia), 1485. Detalle.

Otro tema iconográfico de esta naturaleza es el llamado Encuentro de los tres vivos y los tres muertos. En él, tres hombres jóvenes se encuentran con tres cadáveres en un cruce de caminos. Los tres muertos son un reflejo putrefacto de los vivos (González, 2011, p. 54), este contraste gozó de tremendo éxito en esta época y se da también en la Danza Macabra y en los sepulcros de transi. Igual que en estos, se equipara el cuerpo sano y joven con su reflejo en descomposición.

El Encuentro de los tres vivos y los tres muertos del salterio de Bonne de Luxemburgo, creado en torno a 1350, contemporáneo a la epidemia de peste, nos muestra a tres hombres jóvenes, cuyo alto estatus social queda evidenciado por los ricos ropajes que visten, sus tocados y coronas y el halcón que acompaña a uno de ellos, animal que es un símbolo habitual de riqueza en el arte medieval en alusión a la cetrería. Las figuras están cargadas de expresividad y gesticulan para expresar el horror que sienten ante la visión de los muertos. Los caballos también están aterrorizados y se retuercen tratando de escapar. Los muertos, en diferentes grados de putrefacción, se cubren con sus sudarios e increpan a los vivos mediante gestos. 


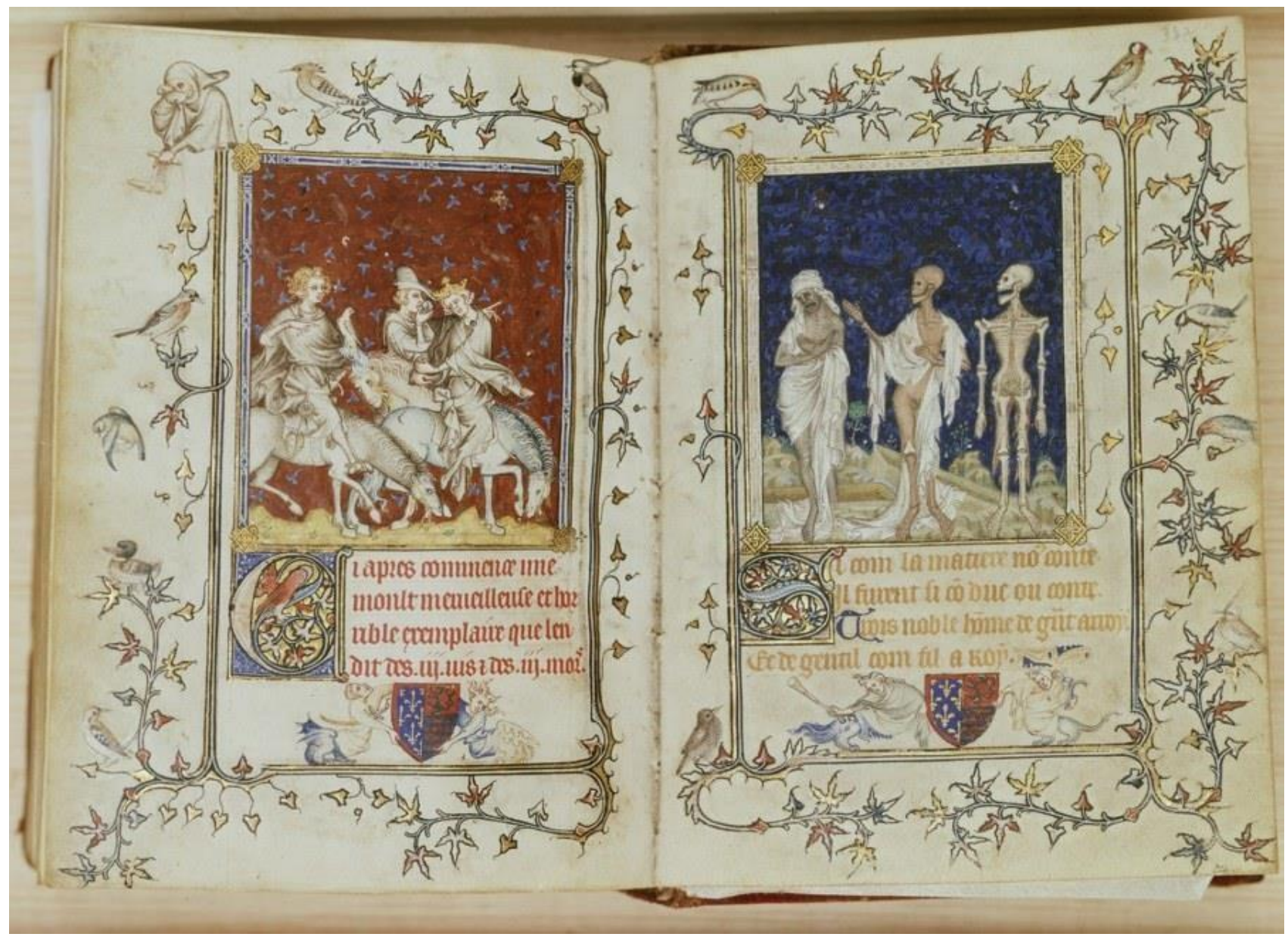

[5] Jean Le Noir (atr.), Salterio de Bonne de Luxemburgo, París (Francia), c. 1345-1350. Nueva York, The Metropolitan Museum of Art, no 69.88, fols. 321v.-322r.

La Danza Macabra y el encuentro de los tres vivos y los tres muertos son algunos de los temas iconográficos más significativos del arte macabro imperante en la Baja Edad Media, pero la muerte, en forma de esqueleto o momia en descomposición, acecha en cualquier esquina: Desde las iniciales de los Libros de Horas hasta las sillerías de coro y aparece jugando al ajedrez en los frescos. Sin embargo, el arte macabro no es el único influjo que tuvo el cambio de mentalidad en las artes. A diferencia de la preferencia por la catedral que había en los siglos anteriores, construida por y para la multitud, destaca a partir de mediados del siglo XIV la capilla. Las capillas eran construidas por un individuo o un pequeño grupo y eran espacios aislados que llamaban al recogimiento y a la oración privada. En muchas ocasiones eran mantenidas por un clero remunerado.

También se dará un auge del retrato, impulsado por la llamada al naturalismo de la corriente filosófica imperante. Las imágenes dejan de ser estereotipos y se buscan los rasgos que diferencian a una persona, en muchos casos son exagerados. En las obras de arte cobra importancia la figura del donante, cuyo tamaño es cada vez mayor y su representación más fiel a la realidad. Pero el propio 
retrato por sí mismo también se establece como género pictórico. En la misma línea, las imágenes se llenan de escudos de los que las han patrocinado para marcar este individualismo que marcará el fin de la Edad Media y que da el primer paso hacia un arte de características renacentistas.

\section{Conclusiones}

Es imposible saber con certeza si el cambio de mentalidad que ocurre a finales de la Baja Edad Media tiene su origen en la serie de catástrofes que azotaron Europa durante el siglo XIV. El pensamiento de Duns Scoto y Guillermo de Ockham, desde luego, es anterior a estas calamidades, así como lo es el origen de los temas iconográficos de la Danza Macabra y el Encuentro de los tres vivos y los tres muertos. Tampoco sabemos si el recién estrenado sentimiento de individualidad y del "yo" cambió la visión que se tenía de la guerra, la peste y el hambre o si este énfasis en el individuo y la persona aislada frente al resto es precisamente un subproducto del sufrimiento al que la sociedad medieval se enfrentó durante este periodo.

Lo que sí es claro es que estas ideas, que en muchos casos son anteriores a la crisis del siglo, se retoman ahora con más fuerza que nunca, se reinterpretan y ajustan para adaptarse a esta nueva realidad. De la misma manera en que se reciclan estos pensamientos y temas artísticos, también se crean nuevas tipologías como el Ars Moriendi, productos de su época que responden a la necesidad de la población. Las nuevas ideas en torno a la devoción privada e intimista tuvieron un fuerte impacto en la manera de percibir la muerte. Esto se traduce en una incorporación de cambios en el ritual funerario y una nueva concepción de los sepulcros

\section{Referencias bibliográficas}

ABERTH, John (2005). The Black Death. The Great Mortality of 1348-1350. A Brief History with Documents. Bedford / St. Martins: Boston.

ARIÈS, Philippe y DUBY, Georges (1989). Historia de la privada vol. 2. De la Europa feudal al Renacimiento. Taurus: Madrid.

CASTELBÓN FERNÁNDEZ, Eva María (1995). "La muerte vivida", Revista de Historia y Arte, $\mathrm{n}^{\circ} 1$, pp. 161-179. 
DUBY, Georges (1998). Arte y sociedad en la Edad Media. Taurus: Madrid.

DUBY, Georges (1986). Europa en la Edad Media. Paidós: Barcelona.

GEESE, Uwe (2004). “La escultura gótica en Francia, Italia, Alemania e Inglaterra” en TOMAN, Rolf (ed.) El Gótico. Ullmann, Barcelona.

GONZÁLEZ ZYMLA, Herbert y BERZAL LLORENTE, Laura Ma (2014). "El transi tomb. Iconografía del yacente en proceso de descomposición”, Revista Digital de Iconografía Medieval, nº13, pp. 67-104.

GONZÁLEZ ZYMLA, Herbert (2014). “La Danza Macabra”, Revista Digital de Iconografía Medieval, $\mathrm{n}^{\circ} 11$, pp. 23-51.

GONZÁLEZ ZYMLA, Herbert (2011). "El encuentro de los tres vivos y los tres muertos", Revista Digital de Iconografía Medieval, nº, pp. 51-82.

HAINDL UGARTE, Ana Luisa (2009). "La muerte en la Edad Media”, Historias del Orbis Terrarum, no 1 , pp. 107-206.

HUETE FUDIO, Mario (1998). "Las actitudes ante la muerte en tiempos de la Peste Negra. La Península Ibérica, 1348-1500”, Cuadernos de Historia Medieval, nº1, pp. 21-58.

HUIZINGA, Johan (2008). El otoño de la Edad Media. Alianza Ensayo: Madrid.

LADERO QUESADA, Miguel Ángel (2004). Las fiestas en la cultura medieval. Areté: Barcelona.

MÂLE, Émil (1982). El arte religioso del siglo XII al XVIII. Fondo de Cultura Económica: Méjico.

ORLANDÍS, José (1998). Historia de la Iglesia vol. 1. Historia de la Iglesia Antigua y Medieval. Palabra: Madrid. 
RUIZ GARCÍA, Elisa (2011). “El Ars Moriendi: Una preparación para el tránsito”, IX Jornadas Científicas sobre Documentación: La muerte y sus testimonios escritos, pp. 315-344.

RUIZ, Teófilo (1998). “The Business of Salvation: Castilian Wills in the Late Middle Ages” en KAGAY, Donald J. y VANN, Theresa M. (eds.). On the Social Origins of Medieval Institutions. Essays in the Honor of Joseph F. O'Callaghan. Brill: Leiden.

TUCHMAN, Barbara (1978). A Distant Mirror. The Calamitous 14th Century. Penguin Books: Londres. 